\title{
A Matching Model with Endogenous Skill Requirements
}

\author{
James Albrecht and Susan Vroman \\ Department of Economics \\ Georgetown University \\ Washington, DC 20057
}

First Version, June 1998

Revised, September 1999

We thank Gerard van den Berg and Åsa Rosén for their comments. 


\section{Introduction}

In this paper, we construct a model that focuses on the role of skill in the labor market. We use our model to examine several explanations that have been given for the increases in wage inequality in the United States and in the United Kingdom and in unemployment in continental Europe that have taken place over the past two decades. ${ }^{1}$

Skill-biased technical change is a common explanation for both of these trends. The argument is that, even though the relative supply of high-skill workers has increased over time in the OECD countries, technical change has shifted demand to an even greater extent in favor of high-skill workers. ${ }^{2}$ A second explanation (e.g., Wood 1994) is that increased trade with developing countries, as opposed to technological factors, lies behind the relative demand shift. In the context of these demand-shift explanations, the different developments in the U.S. and U.K. versus the rest of Europe are ascribed to differences in policy and labor market institutions (Mortensen and Pissarides 1999). Alternatively, some view supply shifts as the basic exogenous force. In this view, an increase in the supply of skilled labor can lead to a change in technology or in the mix of job types (e.g., Beaudry and Green 1999); thus, "supply creates its own demand." A common thread to all these explanations is that aggregate developments in wages and in unemployment are linked to the corresponding developments in the demand for and the supply of skills.

To model these phenomena, we consider a labor market in which some workers are low-skill, while the others are high-skill. We assume that this distribution of worker skills is exogenous. The market is one in which employers create vacancies, which can require either a low skill or a high skill. The distribution of skill requirements across vacancies is endogenous. The technology that we assume is such that a low-skill job can be done by either type of worker, but a high-skill job can only be done by a high-skill worker. Thus, for example, a Ph.D. in nuclear engineering can do rocket science or she can flip hamburgers. A high-school dropout can't do rocket science but

\footnotetext{
${ }^{1}$ Increasing wage inequality both within and across skill groups in the U.S. is documented in, e.g., Bound and Johnson (1992) and Katz and Murphy (1992). For the U.K., see, e.g., Machin (1996). Finally, OECD (1994) documents unemployment trends.

${ }^{2}$ This explanation is proposed in, e.g., Krugman (1994). Berman, Bound, and Machin (1998) develop several of the implications of this explanation and conclude that the data are consistent with these implications.
} 
he can flip hamburgers. By our definition, the Ph.D. is a "high-skill worker," and rocket science is a "high-skill job." This definition of skill makes it possible to talk both about low-skill and high-skill workers and about low-skill and high-skill jobs. ${ }^{3}$ It is intended to capture the fact that many jobs have minimum skill requirements. Workers with a skill level above the minimum required for a job can be hired, but they may not produce more on that job than a worker with less skill. Of course, ours is not the only possible way to think about skill. In particular, one could define skill in terms of efficiency units of labor. Thus, it is often said that a worker is highly skilled if she can complete a job relatively quickly; equivalently, a group of workers is called high-skill if relatively few are required to complete a particular task. This efficiency units definition of skill, while useful for many purposes, is not a natural one for distinguishing between low- and high-skill jobs. ${ }^{4}$

Unemployment is generated in our model by matching frictions. We use a matching process in the spirit of Diamond (1982), Mortensen (1982), and Pissarides (1990) together with a Nash bargaining approach to wage-setting. Our matching process is undirected in the sense that a low-skill worker encounters a high-skill vacancy (and thus is unable to consummate the match) with a probability per unit of time that is proportional to the fraction of vacancies that are high-skill. Similarly, a high-skill worker encounters a lowskill vacancy (which is less suited to her talents) with a probability per unit of time that is proportional to the fraction of vacancies that are low-skill. We use this undirected matching process (as opposed to a process in which lowskill workers can direct their search efforts towards low-skill vacancies, and similarly for high-skill workers) to capture the idea that, given overall labor market conditions, low-skill workers are better off the greater the fraction of vacancies that is low-skill, and vice versa for high-skill workers. Similarly, all else equal, a firm with a low-skill vacancy is better off the greater the fraction of job seekers that are low-skill.

Equilibrium is determined by two free-entry conditions, namely, that the values of maintaining low-skill and high-skill vacancies be zero, plus two steady-state conditions equalizing the flows of the two worker types into and out of unemployment. Depending upon the underlying parameter configura-

\footnotetext{
${ }^{3}$ We have adapted our definition of skill from Vroman (1987). Recent papers that define skill in a similar way include McKenna (1996), Saint-Paul (1996), Mortensen and Pissarides (1999), and Gautier (1999).

${ }^{4}$ Models based on the Roy model, such as Heckman, Lochner, and Taber (1998), also don't allow for the distinction between low and high-skill jobs.
} 
tion, it can take one of two forms. The first type of equilibrium is one in which matches between high-skill workers and low-skill vacancies are mutually beneficial and therefore consummated. In the second type of equilibrium, these potential matches do not form; that is, high-skill workers only take high-skill jobs. We refer to the first case as "equilibrium with cross-skill matching" and to the second case as "equilibrium with ex post segmentation."

Our model generates equilibria with several realistic features. First, we have wage dispersion both within and across skill groups. High-skill workers are paid more on average than low-skill workers are; at the same time, when they match with both types of jobs, they earn more in high-skill jobs than do identical high-skill workers employed in low-skill jobs. ${ }^{5}$ Second, we generate differences in unemployment duration across skill groups. If high-skill workers take low-skill jobs, then unemployment duration among low-skill workers is higher on average than among the highly skilled. If, on the other hand, high-skill workers don't work at low-skill jobs, then this pattern can be reversed. Third, expected vacancy durations are always longer for highskill jobs than for low-skill jobs. Finally, our model generates some of the "crowding out" phenomena examined by van den Berg et. al. (1998). In equilibria with cross-skill matching, high-skill workers "crowd out," i.e., take jobs away from, low-skill workers; however, at the same time, the willingness of the high-skilled to accept low-skill jobs leads to an overall expansion in the supply of low-skill vacancies.

Our model also has interesting comparative statics properties. We examine the effects of (i) increasing the productivity of high-skill jobs (interpreted in the context of our model as skill-biased technical change), (ii) decreasing the productivity of low-skill jobs (interpreted as "cheap import competition"), (iii) changing the underlying worker skill distribution (i.e., shifts in the relative supplies of different worker skill types), (iv) changing the value of leisure, and (v) changing worker bargaining power. The comparative statics effects of skill-biased technical change are particularly striking. Increasing the productivity of high-skill jobs leads to an increase in wage inequality and higher unemployment in cross-skill matching equilibria. In such equilibria, the increased wage inequality takes the form of a decrease in the wage paid to low-skill workers and an increase in the wage paid to high-skill workers

\footnotetext{
${ }^{5}$ Wage dispersion within skill groups is limited to high-skill workers in our model. This is qualitatively consistent with reality insofar as wage dispersion within skill groups is much greater among the more highly skilled.
} 
both on low-skill and high-skill jobs. As the increase in unemployment is concentrated among low-skill workers, skill-biased technical change unambiguously makes high-skill workers better off and low-skill workers worse off even though the productivity of low-skill workers is unchanged. If the skillbiased technical change is large enough to trigger a switch to an ex post segmentation equilibrium, the increase in unemployment is particularly strong. Once the labor market is completely segmented, the effect on unemployment is reversed, but there is still increasing wage inequality. Cheap import competition (i.e., decreasing the productivity of low-skill jobs) has some similar effects; in particular, unemployment rises and there is increased wage dispersion, both within and between skill groups. The major differences are that (i) whereas skill-biased technical change does not affect overall labor market tightness, cheap import competition causes unemployment to rise more rapidly than vacancies and (ii) skill-biased technical change makes high-skill workers better off, but cheap import competition makes these workers worse off.

Several recent papers are related to our model. Perhaps the closest are McKenna (1996) and Gautier (1999). These papers use a definition of skill that is similar to ours and examine equilibria with two worker types and two job types. High-skill workers can apply for both low- and high-skill jobs, but, unlike our approach, low-skill workers are limited to searching for low-skill jobs. More fundamentally, both of these papers use a simpler approach to wage-setting. Rather than determining wages through a Nash bargain, as we do, they assume that wages are determined by a simple sharing rule; namely, wages are a weighted average of the worker's output in the current match and his or her reservation value, which is treated as a constant. This simplified approach has the advantage of making their models more tractable but the considerable disadvantage that wages are unaffected by overall labor market conditions.

Both Acemoglu (1998) and Mortensen and Pissarides (1999) examine the effects of skill-biased technical change in models that are also related to ours. In Acemoglu (1998), as in our model, the fractions of workers who are low-skill and high-skill are exogenously given, as is the relative skill differential. A job's skill level is defined by its physical capital; this is the basic endogenous variable of the model. Again, in common with our approach, Acemoglu (1998) investigates steady-state equilibria with free entry of jobs and an undirected matching process. However, in contrast to our approach, the matching rate in his model is an exogenous constant; that is, the rate 
at which unemployed workers and vacant jobs meet is independent of overall labor market conditions. This leads to conclusions that differ substantially from ours. Specifically, if the skill differential between low-skill and high-skill workers is sufficiently small and/or the fraction of high-skill workers is low enough, all jobs are identical in equilibrium, all potential matches are consummated, the unemployment rates for low-skill and high-skill workers are identical, and the unemployment rate is constant with respect to skill-biased technical change. ${ }^{6}$ The parameter configurations that generate Acemoglu's "pooling equilibria" are roughly analogous to the configurations that generate cross-skill matching in our model. Other parameter configurations, roughly equivalent to those that lead to ex post segmentation in our model, lead to "separating equilibria" in Acemoglu's model. In these equilibria, there are two job types and there is complete segmentation as in our model. In his separating equilibria, however, unemployment rates do not vary with the underlying skill distribution. In Acemoglu's model, skill-biased technical change affects unemployment only when the economy is bumped from a pooling to a separating equilibrium. Relative to our model, Acemoglu (1998) is limited in its ability to examine the effects of skill-biased technical change on wage dispersion. In his pooling equilibria, there is no wage dispersion, and in his separating equilibria, there is no dispersion within skill groups.

Mortensen and Pissarides (1999) also assume an exogenous worker skill distribution and that firms choose skill requirements for vacancies. The key difference relative to our model, aside from endogenizing the rate of job destruction, as in Mortensen and Pissarides (1994), is the assumption that workers are able to direct their search. In equilibrium, there is perfect matching of workers' skills with jobs' skill requirements; that is, in our terms, there is ex post segmentation. This implies that there is no dispersion in initial wages within skill groups ${ }^{7}$ nor do high-skill workers spill over into jobs designed for low-skill workers. In contrast with our model, the interaction between different worker skill groups is thus indirect.

\footnotetext{
${ }^{6}$ For some parameter combinations, our equilibrium in the cross-skill matching case is a corner solution. This corner solution has essentially the same properties as Acemoglu's pooling equilibrium; namely, only low-skill vacancies are created, all potential matches are consummated, and low-skill and high-skill unemployment rates are identical.

${ }^{7}$ As in Mortensen and Pissarides (1994), job productivities depreciate idiosyncratically over time, and wages are continuously renegotiated. This means that workers with a common skill level will be paid different wages on jobs with the same skill requirement, depending on the realized stochastic processes for their jobs' productivities.
} 
There is another, related literature that emphasizes exogenous shifts in the supply of skills rather than in the demand for skills. Machin and Manning (1997) is a paper of this type. Their model is a version of the Burdett and Mortensen (1998) equilibrium search model in which there are two worker types, "good" and "bad," and two corresponding job types. In their model, an exogenous increase in the relative supply of good workers generates an increase in the relative supply of good jobs. A similar effect is present in Acemoglu (1999). In his model, an increase in the supply of high-skill workers leads to changes in technology that in turn increase the demand for skills. In both Machin and Manning (1997) and Acemoglu (1999), an increase in the relative supply of high-skill workers can raise wages and lower unemployment among these workers. Our model also has this feature. As we increase the fraction of high-skill workers, firms respond by creating more high-skill vacancies, and high-skill workers benefit as a result.

We now turn in the next section to the presentation of our model. This is followed, in Section 3, by an analysis of both the cross-skill matching equilibrium and the equilibrium with ex post segmentation. In Section 4, we present an example that illustrates the properties of the model. Finally, in Section 5, we summarize our results and conclude.

\section{The Model}

\subsection{Basic Assumptions}

We consider a continuous-time model in which workers live forever and are risk neutral. The distribution of skills across workers is exogenous. Specifically, we assume a two-point distribution: a fraction $p$ of the workers in the population has the low skill level, $s_{1}$, and a fraction $1-p$ has the high skill level, $s_{2}$. The measure of workers is normalized to one.

Jobs are either vacant or filled. Filled jobs break up at the exogenous rate $\delta$. A job is described by its skill requirement, i.e., by the minimum skill required of a worker hired in the job. The technology is such that when a job is filled, the output produced, $x(s, y)$, is given by

$$
x(s, y)=\left\{\begin{array}{ll}
y & \text { if } \quad s \geqslant y \\
0 & \text { if } \quad s<y
\end{array},\right.
$$

where $s$ is the skill level of the worker in the job and $y$ is the job's skill 
requirement. When a job is filled, its cost is $w(s, y)+c$, the wage paid to the worker plus a fixed cost. If the job is vacant, the fixed cost must still be paid so that the instantaneous cost of a vacancy is $c$. When a vacant job is created, its skill requirement is chosen to maximize the value of the vacancy. Given the technology and the distribution of skills across workers, no skill requirements other than $y_{1}=s_{1}$ and $y_{2}=s_{2}$ will be chosen.

Unemployed workers and vacancies are assumed to meet each other randomly according to a matching function $m(u, v)$, where $u$ is the unemployment rate and $v$ is the measure of vacancies. We assume that the matching function is characterized by constant returns to scale so that

$$
m(u, v)=m\left(1, \frac{v}{u}\right) u=m(\theta) u, \text { where } \theta=\frac{v}{u}
$$

and that $m^{\prime}(\theta)>0$. The arrival rate for workers is thus $m(\theta)$. Low-skill workers meet vacancies at the same rate as high-skill workers do, but they do not qualify for the high-skill vacancies. Let $\phi$ denote the fraction of vacancies that are low-skill; accordingly, the effective arrival rate of employment opportunities for low-skill workers is $\phi m(\theta)$. Similarly, vacancies meet unemployed workers at the rate $\frac{m(\theta)}{\theta}$. We assume that this rate is decreasing in $\theta$. All vacancies face the same arrival rate, but high-skill vacancies meet some workers who are not qualified. Let $\gamma$ denote the fraction of the unemployed who are low-skill; accordingly, the effective arrival rate to high-skill vacancies is $(1-\gamma) \frac{m(\theta)}{\theta}$. Only when low- and high-skill workers find jobs at the same rate will $\gamma=p$. This is generally not the case.

\subsection{Match Formation and Wages}

Matches are consummated between unemployed workers and vacancies whenever the joint surplus that would be realized by the match is nonnegative. In deriving the conditions under which matches are formed, we use the following notation: $U(s)$ is the value of unemployment for a worker of type $s, N(s, y)$ is the value of employment for a worker of type $s$ on a job of type $y, V(y)$ is the value of a vacancy of type $y$, and $J(s, y)$ is the value to the employer of filling a job of type $y$ with a worker of type $s$. Thus, a match will be formed if and only if

$$
N(s, y)+J(s, y) \geqslant U(s)+V(y)
$$


When a match is formed, the wage, $w(s, y)$, is given by the Nash bargaining condition,

$$
N(s, y)-U(s)=\beta[N(s, y)+J(s, y)-U(s)-V(y)],
$$

where $\beta$ is the exogenously given worker's share of the surplus.

We now develop expressions for the various value functions. In doing this, we let $r$ denote the discount rate, which is assumed to be the same for both individuals and firms, $\delta$ the exogenous job dissolution rate, and $b$ the instantaneous value of leisure (or the unemployment benefit).

We begin with the value of employment for a worker of type $s$ on a job requiring skill $y$ :

$$
N(s, y)=\frac{w(s, y)+\delta U(s)}{r+\delta} \quad(\text { conditional on } s \geqslant y)
$$

This expression follows in the usual way from

$$
r N(s, y)=w(s, y)+\delta[U(s)-N(s, y)]
$$

that is, the flow value for a worker of type $s$ who is employed in a job with skill requirement $y$ equals the sum of the flow return, $w(s, y)$, plus the expected instantaneous capital loss, $\delta[U(s)-N(s, y)]$.

Similarly, the value to a firm of having a job with skill requirement $y$ filled by a worker of type $s$ is

$$
J(s, y)=\frac{y-w(s, y)-c+\delta V(y)}{r+\delta} \quad(\text { conditional on } s \geqslant y) .
$$

The values of unemployment for low- and high-skill workers are implicitly defined by

$$
\begin{gathered}
r U\left(s_{1}\right)=b+m(\theta) \phi\left[N\left(s_{1}, s_{1}\right)-U\left(s_{1}\right)\right] \\
r U\left(s_{2}\right)=b+m(\theta)\left\{\phi \max \left[N\left(s_{2}, s_{1}\right)-U\left(s_{2}\right), 0\right]+(1-\phi)\left[N\left(s_{2}, s_{2}\right)-U\left(s_{2}\right)\right]\right\} .
\end{gathered}
$$

The value of unemployment for low-skill workers incorporates the assumption that low-skill workers cannot do high-skill jobs; thus, the arrival rate of jobs that these workers can do is $m(\theta) \phi$. Similarly, the value of unemployment for 
high-skill workers incorporates the assumption that these workers are capable of undertaking either low-skill or high-skill jobs. The former arrive at rate $m(\theta) \phi$, and the latter arrive at rate $m(\theta)(1-\phi)$. It may not be worthwhile for high-skill workers to be employed on low-skill jobs; this is why the value associated with the arrival of a low-skill vacancy is $\max \left[N\left(s_{2}, s_{1}\right)-U\left(s_{2}\right), 0\right]$.

Finally, the values of low- and high-skill vacancies are

$V\left(s_{1}\right)=-c+\frac{m(\theta)}{\theta}\left\{\gamma\left[J\left(s_{1}, s_{1}\right)-V\left(s_{1}\right)\right]+(1-\gamma) \max \left[J\left(s_{2}, s_{1}\right)-V\left(s_{1}\right), 0\right]\right\}$

$$
V\left(s_{2}\right)=-c+\frac{m(\theta)}{\theta}(1-\gamma)\left[J\left(s_{2}, s_{2}\right)-V\left(s_{2}\right)\right],
$$

respectively. The value of a low-skill vacancy reflects the assumption that while both worker types are capable of doing the low-skill job, it may not be worthwhile for high-skill workers to take these jobs; i.e., the value of meeting a high-skill unemployed worker is $\max \left[J\left(s_{2}, s_{1}\right)-V\left(s_{1}\right), 0\right]$. Similarly, the expression for the value of a high-skill vacancy reflects the assumption that only high-skill workers are able to perform these jobs; thus, the effective arrival rate to high-skill vacancies is $\frac{m(\theta)}{\theta}(1-\gamma)$. Since this is a long-run model with free entry and exit, the values of both vacancy types must be zero; i.e., $V\left(s_{1}\right)=V\left(s_{2}\right)=0$.

Returning to inequality (1) and substituting, a match will be formed if and only if

$$
y-c \geqslant r U(s) \quad \text { (conditional on } s \geqslant y) .
$$

Similarly, from equation (2), the wage of a worker of type $s$ on a job requiring skill $y$ can be expressed as

$$
w(s, y)=\beta(y-c)+(1-\beta) r U(s) \quad(\text { conditional on } y-c \geqslant r U(s)) .
$$

The wage is thus a weighted average of the net output of the match (output minus the fixed cost) and the worker's flow value of unemployment. At most three wages are paid in equilibrium, namely,

$$
\begin{aligned}
& w\left(s_{1}, s_{1}\right)=\beta\left(s_{1}-c\right)+(1-\beta) r U\left(s_{1}\right) \\
& w\left(s_{2}, s_{1}\right)=\beta\left(s_{1}-c\right)+(1-\beta) r U\left(s_{2}\right) \\
& w\left(s_{2}, s_{2}\right)=\beta\left(s_{2}-c\right)+(1-\beta) r U\left(s_{2}\right) .
\end{aligned}
$$


High-skill workers are always paid more than low-skill workers. If high-skill workers take low-skill jobs, that is, if the expression for $w\left(s_{2}, s_{1}\right)$ is relevant, then they receive a higher wage on these jobs than low-skill workers do. ${ }^{8}$ This is because high-skill workers have a more valuable outside option than low-skill workers do; i.e., $r U\left(s_{2}\right)>r U\left(s_{1}\right)$. High-skill workers, however, earn a lower wage on low-skill jobs than they do on high-skill jobs. This simply reflects the different productivities on the two types of job. Finally, note that equation (4), together with the equilibrium conditions, $V\left(s_{1}\right)=V\left(s_{2}\right)=0$, imply that

$$
J(s, y)=\frac{(1-\beta)[y-c-r U(s)]}{r+\delta}
$$

\section{Equilibrium}

The nature of equilibrium depends on the parameters of the model. There are two cases to consider. The first is an equilibrium in which it is beneficial for high-skill workers to match with low-skill vacancies; the second is an equilibrium in which it is not worthwhile for high-skill workers to take low-skill jobs. We refer to the first case as equilibrium with cross-skill matching and to the second as equilibrium with ex post segmentation. We show that if the parameters of the model are consistent with cross-skill matching, then there is a unique equilibrium of this type. Similarly, if the parameters of the model are consistent with ex post segmentation, there is a unique equilibrium of that type. For some parameter configurations, a cross-skill matching equilibrium and an ex post segmentation equilibrium can coexist; that is, for some parameter configurations, we need to consider the possibility of multiple equilibria.

We begin with a derivation of the cross-skill matching equilibrium, followed by the ex post segmentation equilibrium. Next, we briefly discuss the possibility of multiple equilibria. Finally, we conclude this section with an analysis of the comparative statics of skill-biased technical change.

\footnotetext{
${ }^{8}$ Evidence for this phenomenon can be found in, e.g., Sicherman (1991) and van den Berg et. al. (1998).
} 


\subsection{Cross-Skill Matching}

To solve for equilibrium, we need to find the equilibrium values of the four endogenous variables, $\phi, \gamma, u$, and $\theta$. These are found using (i) two steadystate conditions and (ii) the two zero-value conditions given above. The first steady-state condition is that the flow of low-skill workers out of unemployment equals the flow of low-skill workers back into unemployment:

$$
\phi m(\theta) \gamma u=\delta(p-\gamma u) .
$$

Since $\phi m(\theta)$ is the arrival rate of vacancies with low skill requirements and $\gamma$ is the fraction of the unemployed who are low skill, the flow of low-skill workers out of unemployment is $\phi m(\theta) \gamma u$. The corresponding flow into unemployment is $\delta$ times the measure of employed low-skilled workers. This latter measure is $p-\gamma u$, the measure of low-skilled workers in the population (recall that we normalized the total measure of workers to 1) minus the measure of these workers who are unemployed.

The second steady-state condition is that the flow of high-skill workers out of unemployment equals the flow of high-skill workers back into unemployment:

$$
m(\theta)(1-\gamma) u=\delta(1-p-(1-\gamma) u)
$$

In cross-skill matching equilibrium, high-skill workers face an arrival rate of vacancies of $m(\theta)$, and the measure of high-skill unemployed is $(1-\gamma) u$; thus the flow of high-skill workers out of unemployment is $m(\theta)(1-\gamma) u$. There are $1-p$ high-skill workers, of whom $(1-\gamma) u$ are unemployed. The flow of high-skill workers into unemployment is thus $\delta(1-p-(1-\gamma) u)$.

Equations (10) and (11) can be used to solve for $\phi$ and $u$ as functions of $\theta$ and $\gamma$; namely,

$$
\phi=\frac{(1-\gamma) p m(\theta)+(p-\gamma) \delta}{m(\theta) \gamma(1-p)}
$$

and

$$
u=\frac{\delta(1-p)}{(1-\gamma)(\delta+m(\theta))} .
$$

Note that $\phi$ is decreasing in $\gamma$ and increasing in $\theta$, the latter so long as $\gamma>p$. This condition is necessarily satisfied when high-skill workers take low-skill 
jobs since, in that case, their exit rate from unemployment is greater than the corresponding rate for low-skill workers. ${ }^{9}$

Equilibrium also requires that $V\left(s_{1}\right)=0$ and $V\left(s_{2}\right)=0$. From equations (7), (8), and (9), these conditions can be written respectively as

$$
-c+\frac{m(\theta)}{\theta}\left[\gamma\left(\frac{(1-\beta)\left[s_{1}-c-r U\left(s_{1}\right)\right]}{r+\delta}\right)+(1-\gamma)\left(\frac{(1-\beta)\left[s_{1}-c-r U\left(s_{2}\right)\right]}{r+\delta}\right)\right]=0
$$

$$
-c+\frac{m(\theta)}{\theta}(1-\gamma)\left(\frac{(1-\beta)\left[s_{2}-c-r U\left(s_{2}\right)\right]}{r+\delta}\right)=0 .
$$

Equation (14) uses the assumption that it is worthwhile for high-skill workers to take low-skill jobs, i.e., that $J\left(s_{2}, s_{1}\right)>0$.

All that remains is to substitute for the two unemployment values. Using equations (3), (5), and (6) together with $N\left(s_{2}, s_{1}\right)>U\left(s_{2}\right)$ gives

$$
\begin{gathered}
r U\left(s_{1}\right)=\frac{b(r+\delta)+m(\theta) \phi \beta\left(s_{1}-c\right)}{r+\delta+m(\theta) \phi \beta} \\
r U\left(s_{2}\right)=\frac{b(r+\delta)+\beta m(\theta)\left[\phi s_{1}+(1-\phi) s_{2}-c\right]}{[r+\delta+\beta m(\theta)]} .
\end{gathered}
$$

Equations (16) and (17) show that the flow values of unemployment for the two worker types equal weighted averages of the flow value of leisure and their respective flow values of employment. Note that $r U\left(s_{1}\right)$ is increasing in both $\theta$ and $\phi$, while $r U\left(s_{2}\right)$ is increasing in $\theta$ but decreasing in $\phi$. Holding the skill mix of vacancies constant, both worker types are better off as the ratio of vacancies to unemployment increases. Holding overall labor market conditions constant, low-skill workers are better off the greater the fraction of vacant jobs that is low-skill and high-skill workers are better off the smaller is this fraction.

We can now use the zero-value conditions to find the equilibrium. It is more convenient, however, to work with the equivalent conditions $V\left(s_{1}\right)=$ $V\left(s_{2}\right)$ and $V\left(s_{2}\right)=0$. We can then reduce the cross-skill matching case to

\footnotetext{
${ }^{9}$ Another way to establish that $\gamma>p$ when there is cross-skill matching is to use the requirement that $\phi$ be a fraction or equivalently that $1-\phi=\frac{(\gamma-p)(\delta+m(\theta))}{m(\theta) \gamma(1-p)}>0$.
} 
a single equation in $\theta$, which can be solved analytically. The first of these conditions (the "equal-value condition") can be written as

$$
\gamma\left(s_{1}-c-r U\left(s_{1}\right)\right)-(1-\gamma)\left(s_{2}-s_{1}\right)=0
$$

Using the expression for $r U\left(s_{1}\right)$ from equation (16), we have

$$
s_{1}-c-r U\left(s_{1}\right)=\frac{\left(s_{1}-c-b\right)(r+\delta)}{r+\delta+\beta m(\theta) \phi},
$$

so the equal-value condition can be expressed as

$$
\left(s_{1}-c-b\right)(r+\delta)=(1-\gamma)\left[\left(s_{2}-c-b\right)(r+\delta)+\beta m(\theta) \phi\left(s_{2}-s_{1}\right)\right] .
$$

From equation (17) we have

$$
s_{2}-c-r U\left(s_{2}\right)=\frac{\left(s_{2}-c-b\right)(r+\delta)+\beta m(\theta) \phi\left(s_{2}-s_{1}\right)}{r+\delta+\beta m(\theta)} .
$$

Inserting this into the second condition that $V\left(s_{2}\right)=0$ (i.e., equation (15)) and using equation (18) gives

$$
c=\frac{m(\theta)}{\theta} \frac{(1-\beta)\left(s_{1}-c-b\right)}{r+\delta+\beta m(\theta)},
$$

which, given our assumptions on $m(\theta)$, has a unique solution for $\theta$. If we insert this solution into the equal-value condition or into $V\left(s_{2}\right)=0$, recognizing that $\phi=\phi(\theta, \gamma)$, we then get a quadratic in $\gamma$. This quadratic has a unique solution consistent with $1>\gamma>p$.

Note that, since neither $s_{2}$ nor $p$ enter into equation (19), $\frac{\partial \theta}{\partial s_{2}}=0$ and $\frac{\partial \theta}{\partial p}=0$; that is, in the cross-skill matching equilibrium, neither skill-biased technical change nor a change in the skill composition of the workforce affects overall labor market tightness. ${ }^{10}$ In addition, since $m^{\prime}(\theta)>0$ and $\frac{d \frac{m(\theta)}{\theta}}{d \theta}<$

\footnotetext{
${ }^{10}$ As we show below, however, in contrast with Acemoglu (1998), the unemployment rate does vary with changes in these parameters.
} 
0 , it is easy to show that $\frac{\partial \theta}{\partial s_{1}}>0, \frac{\partial \theta}{\partial b}<0, \frac{\partial \theta}{\partial c}<0, \frac{\partial \theta}{\partial \beta}<0, \frac{\partial \theta}{\partial r}<0$, and $\frac{\partial \theta}{\partial \delta}<0$. In principle, we can also derive comparative statics effects for $\gamma$ as well as for $\phi$ and $u$, but the expressions become too cumbersome to evaluate.

Before turning to the ex post segmentation case, we need to take into account the possibility that the cross-skill matching equilibrium will be a corner solution. Specifically, if $p$ is sufficiently large and/or $s_{2}-s_{1}$ is sufficiently small, the solution will be one in which only low-skill vacancies are offered; i.e., $\phi=1$. In this case, the model simplifies in the following ways:

$$
\begin{gathered}
r U\left(s_{1}\right)=r U\left(s_{2}\right)=\frac{b(r+\delta)+\beta m(\theta)\left(s_{1}-c\right)}{r+\delta+\beta m(\theta)} . \\
J\left(s_{1}, s_{1}\right)=J\left(s_{2}, s_{1}\right)=\frac{(1-\beta)\left(s_{1}-c-b\right)}{r+\delta+\beta m(\theta)} .
\end{gathered}
$$

The condition that $V\left(s_{1}\right)=0$ (the condition that $V\left(s_{2}\right)=0$ is no longer relevant) then simply reduces to equation (19). In the corner solution, the value of opening a high-skill vacancy must be negative. The condition on the parameters that ensures this is

$$
s_{1}-c-b>(1-p)\left[s_{2}-c-b+\frac{\beta m\left(\theta^{*}\right)\left(s_{2}-s_{1}\right)}{r+\delta}\right],
$$

where $\theta^{*}$ is the value of $\theta$ that solves equation (19). Since $\theta^{*}$ is independent of $p$, for $p$ sufficiently close to one, no high-skill jobs will be present in the economy. Similarly, for fixed $p$, since $\theta^{*}$ is independent of $s_{2}$, the above inequality is necessarily satisfied for $s_{2}-s_{1}$ sufficiently small.

Finally, the cross-skill matching equilibrium that we have derived is conditional on the parameters of the model being such that it is, in fact, worthwhile for high-skill workers to match with low-skill vacancies. That is, we need to check that $s_{1}-c \geq r U\left(s_{2}\right)$. The cross-skill matching equilibrium is more likely to be relevant (i) the smaller the spread between the productivities on low- and high-skill jobs (the smaller is $s_{2}-s_{1}$ ) and/or (ii) the greater the fraction of the workforce that is low-skill (the larger is $p$ ). ${ }^{11}$

\footnotetext{
${ }^{11}$ Of course, the existence of a cross-skill matching equilibrium also depends on the values of other parameters. For example, a higher value of $c$ makes the cross-skill matching equilibrium more likely. Further, for sufficiently large $c$, the solution will be at the corner.
} 
In Section 4, we illustrate the properties of cross-skill matching equilibrium by solving the model using a specific functional form for $m(\theta)$ and specific parameter values. In the context of specific examples, we can check that the inequality $s_{1}-c \geq r U\left(s_{2}\right)$ is indeed satisfied. Before doing this, however, we analyze the ex post segmentation case.

\subsection{Ex Post Segmentation}

In this case, high-skill workers match only with high-skill vacancies. This requires $s_{1}-c<r U\left(s_{2}\right)$. The first step in solving for this equilibrium is to use the steady-state conditions to derive the relationships between $\theta, \phi, \gamma$, and $u$. The steady-state conditions are now

$$
\begin{aligned}
\phi m(\theta) \gamma u & =\delta(p-\gamma u) \\
(1-\phi) m(\theta)(1-\gamma) u & =\delta[(1-p)-(1-\gamma) u] .
\end{aligned}
$$

Note that the steady-state condition for low-skill workers is the same as in the cross-skill matching case; that is, equations (10) and (20) are identical. The steady-state condition for high-skill workers, equation (21), is changed, however, reflecting the fact that in ex post segmentation equilibrium, highskill workers only match with high-skill vacancies. The two new steady-state conditions can be solved for $u$ and $\phi$ in terms of $\theta$ and $\gamma$ :

$$
\begin{gathered}
u=\frac{\delta(\gamma+p-2 \gamma p)}{\gamma(1-\gamma)[m(\theta)+2 \delta]} \\
\phi=\frac{p(1-\gamma) m(\theta)+\delta(p-\gamma)}{m(\theta)(\gamma+p-2 \gamma p)} .
\end{gathered}
$$

Note that $\phi$ is decreasing in $\gamma$. Of course, $\phi$, the fraction of vacancies that are low skill, must lie between 0 and 1 . After solving for equilibrium, we check to make sure that this condition is satisfied.

To solve the zero-value conditions, we need the unemployment values for each type of worker. Assuming that $s_{1}-c<r U\left(s_{2}\right)$, these values are implicitly defined by

$$
r U\left(s_{1}\right)=b+m(\theta) \phi\left[N\left(s_{1}, s_{1}\right)-U\left(s_{1}\right)\right]
$$




$$
r U\left(s_{2}\right)=b+m(\theta)(1-\phi)\left[N\left(s_{2}, s_{2}\right)-U\left(s_{2}\right)\right] .
$$

The expression for the value of unemployment for high-skill workers incorporates the assumption that these workers do not match with low-skill vacancies. Substituting for $N\left(s_{1}, s_{1}\right)$ and $N\left(s_{2}, s_{2}\right)$ and solving yields

$$
\begin{gathered}
r U\left(s_{1}\right)=\frac{b(r+\delta)+m(\theta) \phi \beta\left(s_{1}-c\right)}{r+\delta+m(\theta) \phi \beta} \\
r U\left(s_{2}\right)=\frac{b(r+\delta)+\beta m(\theta)(1-\phi)\left(s_{2}-c\right)}{r+\delta+\beta m(\theta)(1-\phi)} .
\end{gathered}
$$

The flow unemployment values are again weighted averages of the flow value of leisure and the respective flow values of employment. The change in the expression for $r U\left(s_{2}\right)$, relative to the cross-skill matching case, reflects the fact that, in ex post segmentation equilibrium, high-skill workers only work at high-skill jobs. Note that $r U\left(s_{1}\right)$ is increasing in both $\theta$ and $\phi$, whereas $r U\left(s_{2}\right)$ is increasing in $\theta$ but decreasing in $\phi$.

The zero-value conditions in the ex post segmentation case are

$$
\begin{gathered}
V\left(s_{1}\right)=-c+\frac{m(\theta)}{\theta} \gamma J\left(s_{1}, s_{1}\right)=0 \\
V\left(s_{2}\right)=-c+\frac{m(\theta)}{\theta}(1-\gamma) J\left(s_{2}, s_{2}\right)=0 .
\end{gathered}
$$

The expression for $V\left(s_{1}\right)$ incorporates the assumption that only low-skill workers take low-skill jobs. Using $J(s, y)=\frac{(1-\beta)(y-c-r U(s))}{r+\delta}$ and the expressions for the unemployment values gives the two zero-value conditions:

$$
\begin{gathered}
V\left(s_{1}\right)=-c+\frac{m(\theta)}{\theta} \gamma\left[\frac{(1-\beta)\left(s_{1}-c-b\right)}{r+\delta+m(\theta) \phi \beta}\right]=0 \\
V\left(s_{2}\right)=-c+\frac{m(\theta)}{\theta}(1-\gamma)\left[\frac{(1-\beta)\left(s_{2}-c-b\right)}{r+\delta+m(\theta)(1-\phi) \beta}\right]=0 .
\end{gathered}
$$

The zero-value condition for low-skill vacancies is decreasing in $\theta$ (since $\frac{m(\theta)}{\theta}$ is decreasing in $\theta$ and, from equation $(23), m(\theta) \phi$ is increasing in $\theta$ ) and 
increasing in $\gamma$ (since $\phi$ is decreasing in $\gamma$ ), and the zero-value condition for high-skill vacancies is decreasing in both $\theta$ and $\gamma$. This is exactly as intuition would suggest. As overall labor market conditions tighten (i.e., as $\theta$ increases), the value of either type of vacancy must fall. Holding overall labor market conditions constant, as the fraction of low-skill workers among the unemployed increases, the value of low-skill vacancies increases, while that of high-skill vacancies decreases. The $V\left(s_{1}\right)=0$ locus is thus upward sloping in the positive quadrant of the $(\theta, \gamma)$ plane, while the $V\left(s_{2}\right)=0$ locus is downward sloping. This implies that if the parameters of the model are consistent with ex post segmentation, (for example, if $p$ is small and/or $s_{2}-s_{1}$ is large), there will be a unique equilibrium of this type. In Section 4 , this equilibrium will also be demonstrated.

\subsection{Multiple Equilibria}

In order that ex post segmentation occur, it must be worthwhile for highskill workers to match only with high-skill vacancies; that is, $s_{1}-c<r U\left(s_{2}\right)$ must hold. Similarly, cross-skill matching requires $s_{1}-c>r U\left(s_{2}\right)$. Multiple equilibria can arise because the value of unemployment for an individual high-skill worker depends on the choices made by other high-skill workers. If all high-skill workers, save possibly one, match only with high-skill vacancies, then employers respond by creating more high-skill vacancies. This increases the value of unemployment for the individual high-skill worker; thus ex post segmentation becomes more likely. On the other hand, if all high-skill workers, again save possibly one, match indiscriminately, that is, accept any type of job, then employers respond by shifting the vacancy mix in favor of low-skill jobs. Accordingly, cross-skill matching obtains for a wider range of parameter values.

Multiple equilibria are thus generated by a coordination externality. It is important to understand, however, that multiple equilibria do not occur

for all possible parameter configurations. For some parameter values (e.g., if $p$ is large and/or $s_{2}-s_{1}$ is small), it would be worthwhile for an individual high-skill worker to accept a low-skill job, even if all other high-skill workers were to reject such jobs. In such cases, there is a unique equilibrium, and it is one with cross-skill matching. For other parameter values (e.g., if $p$ is small and/or $s_{2}-s_{1}$ is large), it would be worthwhile for an individual high-skill worker to reject low-skill job offers, even if all other high-skill workers were to accept such jobs. In such cases, there is a unique equilibrium, and it entails 
ex post segmentation. For an intermediate range of parameter values, two equilibria exist simultaneously, one with cross-skill matching and one with ex post segmentation. The example that we develop in Section 4 provides some intuition for the conditions under which the various equilibrium possibilities obtain.

\subsection{Comparative Statics}

To analyze the effects of a change in any of the model's parameters, we need to examine the effects (i) on the movement from one cross-skill matching equilibrium to another, (ii) on the movement from one ex post segmentation equilibrium to another, and (iii) on the switch from cross-skill matching to ex post segmentation, or vice versa. Since we are most interested in the comparative statics effects of skill-biased technical change, we focus on the effects of increasing $s_{2}$. Suppose to begin that the parameter configuration is such that there is only a cross-skill matching equilibrium. This is illustrated in Figure 1 by the intersection of the two zero-value loci. The set of $(\theta, \gamma)$ combinations such that $V\left(s_{1}\right)=0$ is upward sloping; the corresponding set of points such that $V\left(s_{2}\right)=0$ slopes downward. The intuition is the same as that given in the discussion of ex post segmentation equilibria above.

Now consider the effects of an increase in $s_{2}$. Assuming that the new parameter configuration is still consistent with cross-skill matching, the direct effect is to shift the $V\left(s_{2}\right)=0$ locus to the right. The reason is that, with the increase in $s_{2}$, high-skill firms get more output from their workers. For any particular skill composition among the unemployed (i.e., for any given value of $\gamma$ ), a higher value of $\theta$ (i.e., worse overall labor market conditions from the employer's point of view) is now consistent with zero value for high-skill vacancies. In addition to this direct effect, the increase in $s_{2}$ also has an effect on low-skill firms. The reason is that all high-skill workers share in the rents generated by the increase in $s_{2}$ and, as a result, the value of unemployment for these workers increases. This means that a high-skill worker matching with a low-skill vacancy has a better outside option, so the low-skill firm has to pay this worker more. Low-skill firms are thus worse off as a result of the increase in $s_{2}$, as shown in Figure 1 by the leftward shift in the $V\left(s_{1}\right)=0$ locus. As can be seen in Figure 1, an increase in $s_{2}$ causes the fraction of low-skill workers among the unemployed to increase $\left(\frac{\partial \gamma}{\partial s_{2}}>0\right)$. The fact that the two loci shift in opposite directions means that the effect on $\theta$ is 
unclear, but as we know from equation (19), these effects cancel since we have $\frac{\partial \theta}{\partial s_{2}}=0$. We can also see from equations (12) and (13) that an increase in $s_{2}$, decreases the fraction of vacancies that are low-skill $\left(\frac{\partial \phi}{\partial s_{2}}<0\right)$ and increases unemployment $\left(\frac{\partial u}{\partial s_{2}}>0\right)$.

Increases in $s_{2}$ eventually shift the economy from a cross-skill matching equilibrium to one with ex post segmentation. At this point, high-skill workers stop matching with low-skill vacancies in favor of specializing in high-skill employment. There is a discrete fall in the value of low-skill vacancies (since high-skill workers are no longer available as potential matches) and a discrete rise in the value of high-skill vacancies (since now no high-skill workers are siphoned off to low-skill jobs). The vacancy mix changes (specifically, $\phi$ falls) to restore the zero-value conditions. Since fewer low-skill vacancies are opened, unemployment among low-skill workers increases. The effect on high-skill unemployment cannot be determined in general. On the one hand, the availability of more high-skill vacancies decreases high-skill unemployment; on the other hand, high-skill unemployment increases since high-skill workers no longer match with low-skill vacancies. For movements from crossskill matching to ex post segmentation that are caused by small increases in $s_{2}$, we expect the second effect to dominate. That is, we expect overall unemployment to increase. If unemployment increases for both skill groups, the effect of the shift between equilibrium types on $\gamma$ is ambiguous. Finally, the effect on overall labor market tightness cannot be signed in general. Unemployment is likely to increase in the movement from cross-skill matching to ex post segmentation, but vacancies are also likely to increase.

The ex post segmentation equilibrium can be viewed as the intersection of two zero-value loci defined by equations (26) and (27). As in the cross-skill matching case, skill-biased technical change has the direct effect of making high-skill vacancies more profitable; thus, as in Figure 1, the $V\left(s_{2}\right)=0$ locus would shift to the right. Unlike the cross-skill matching case, however, the increase in $s_{2}$ has no indirect effect on the value of low-skill vacancies. This is because, with ex post segmentation, the low-skill and high-skill markets are essentially independent; in particular, an increase in the value of unemployment for high-skill workers has no effect on the value of low-skill vacancies, i.e., the $V\left(s_{1}\right)=0$ locus does not shift. Thus, with ex post segmentation, skill-biased technical change increases both $\theta$ and $\gamma$. Equations (22) and (23) 
give $\phi$ and $u$ as functions of $\theta$ and $\gamma$. In general, the effect of an increase in $s_{2}$ on these two variables cannot be signed.

In the next section, we present an example of the model, which illustrates these comparative statics effects, as well as the effects of varying other parameters.

\section{An Example}

The example uses the matching function, $m(u, v)=2 \sqrt{u \cdot v}$, that is, $m(\theta)=$

$2 \sqrt{\theta}$, and in the baseline case, we assume that $s_{1}=1, s_{2}=1.2, p=\frac{2}{3}, b=.1$, $\beta=.5, \delta=.2, c=.3$, and $r=.05$. The baseline parameter values were chosen with three criteria in mind. First, the parameter values themselves should be reasonable. Second, the values of the endogenous variables that follow from these parameter values should also be reasonable. Finally, our baseline parameters should be such that plausible variations illustrate the various equilibrium and comparative statics possibilities that we have identified. We focus, however, on cross-skill matching equilibria. We do this because this type of equilibrium is relatively novel and because in a richer model with more than two skill levels, this would be the more relevant equilibrium concept.

Table 1 presents the solution for our baseline case (in row 1, panel 1) and the comparative statics of skill-biased technical change (in subsequent rows and in panel 2). In the baseline case, there is a unique equilibrium, and it is one with cross-skill matching. The most striking feature of this case is that almost all vacancies are low-skill $(\phi=.983)$. The reasons for this are that (i) most workers are low-skill $\left(p=\frac{2}{3}\right)$ and (ii) high-skill jobs are only twenty percent more productive than low-skill jobs. Since there are very few high-skill vacancies, the rate at which high-skill workers find jobs is only slightly above the corresponding rate for low-skill workers. This leads to an outcome in which low-skill workers are only slightly overrepresented in the pool of unemployed $(\gamma=.670)$. This further implies that high-skill workers, when they are employed, are typically working at low-skill jobs. Low-skill and high-skill workers' unemployment rates are almost identical, and when they are employed, the two worker types are almost equally productive. As a result, the unemployment values for low-skill and high-skill workers are almost identical. This explains why $w_{11}$, the wage that a low-skill worker receives on a low-skill job, and $w_{12}$, the wage that a high-skill worker receives on a low-skill job, are essentially the same. Of course, the few fortunate high- 
skill workers who find one of the rare high-skill jobs earn substantially more than they would have earned on a low-skill job. For the high-skill worker, the wage premium associated with the high-skill job, $w_{22}-w_{21}$, is precisely one half of the productivity increment, $s_{2}-s_{1}$. This follows from our assumption that $\beta=0.5$. Finally, the last column shows aggregate output $(Y)$, computed as $s_{1}$ times low-skill employment plus $s_{2}$ times high-skill employment. Since almost all employment is low-skill, $Y$ is only slightly greater than total employment (i.e., $1-u$ ).

Table 1: Comparative Statics for $s_{2}$

Solution with $m(\theta)=2 \theta^{\frac{1}{2}}$

\begin{tabular}{ccccccccccc}
\multicolumn{10}{c}{ Cross-Skill Matching Equilibria } \\
$s_{2}=1, p=\frac{2}{3}, b=.1, \beta=.5, \delta=.2, c=.3$ \\
$s_{2}$ & $\theta$ & $m(\theta)$ & $u$ & $\gamma$ & $\phi$ & $w_{11}$ & $w_{21}$ & $w_{22}$ & $Y$ \\
1.20 & 1.68 & 2.59 & .072 & .670 & .983 & .651 & .653 & .753 & .929 \\
1.25 & 1.68 & 2.59 & .079 & .696 & .866 & .645 & .666 & .791 & .932 \\
1.30 & 1.68 & 2.59 & .084 & .716 & .779 & .640 & .679 & .829 & .936 \\
1.35 & 1.68 & 2.59 & .089 & .732 & .711 & .636 & .694 & .869 & .942 \\
\multicolumn{8}{c}{ Ex } & Post & Segmentation Equilibria \\
$s_{2}$ & $\theta$ & $m(\theta)$ & $u$ & $\gamma$ & $\phi$ & $w_{11}$ & $w_{21}$ & $w_{22}$ & $Y$ \\
1.30 & 1.71 & 2.62 & .130 & .631 & .545 & .622 & -- & .867 & .956 \\
1.35 & 1.76 & 2.65 & .129 & .638 & .537 & .622 & -- & .913 & .972 \\
1.40 & 1.80 & 2.69 & .128 & .644 & .528 & .621 & -- & .958 & .987
\end{tabular}

The baseline case generates an unemployment rate of about $7 \%$, and the unemployment rates for the two skill groups are essentially the same. The equilibrium value of $\theta=1.68$ implies a steady-state measure of vacancies of $v=.12$. The average duration of unemployment is slightly more than four and one half months $(12 \times(1 / 2.59)=4.63)$, while the average duration of a vacancy is close to 8 months $(12 \times(1.68 / 2.59)=7.78){ }^{12}$ (The average duration of a high-skill vacancy is approximately twice that of a low-skill vacancy, but almost all vacancies are low-skill.) Note finally that even though jobs are vacant for nearly eight months on average and that the fixed cost, $c$, is incurred whether the job is occupied or not, once the vacancy is filled,

\footnotetext{
${ }^{12}$ While both $\theta$ and average vacancy duration are high, we note that the model does not include the option of on-the-job search. If we were to allow for this, the model would generate more "realistic" numbers.
} 
more than half of the output generated by the match goes to the worker in the form of wages. For example, when a low-skill worker is employed on a low-skill job, a flow output of $s_{1}=1.0$ is generated. Sixty-five percent of this flow output goes to the worker as a wage, $30 \%$ is required to cover the fixed cost, so only $5 \%$ is left as profit. The fact that employers are squeezed in this way is a result of our assumption that the value of maintaining either type of vacancy must be zero. On average, a low-skill vacancy generates a cost of $c=0.3$ for a bit less than eight months, and this is followed by a profit of about 0.05 for five years. Discounting using an interest rate of $r=0.05$ equalizes these expected flows.

The rest of Table 1 shows the comparative statics effects of skill-biased technical change. As noted above, increasing $s_{2}$ in cross-skill matching equilibrium has no effect on $\theta$. This can be seen in panel 1 . While there is no effect on $\theta$, widening the productivity gap does have dramatic effects. Comparing rows 1 and 2 of panel 1, there is a striking decrease in $\phi$ from .983 to .866 . Since there are now more vacancies for which the low-skilled are unqualified, the fraction of low-skill workers among the unemployed goes up; specifically, $\gamma$ increases from .670 to .696. Accordingly, the average duration of unemployment among low-skill workers increases, and the value of unemployment for these workers falls. This in turn implies that the wage of low-skill workers must fall (.651 in row 1 versus .645 in row 2). High-skill workers, on the other hand, are, of course, better off as $s_{2}$ increases. As $\phi$ decreases, unemployed high-skill workers are more likely to match with a high-skill job, so the value of unemployment among the high-skilled increases. As a result, the wages of high-skill workers on both low- and high-skill jobs increase. The wage increase for high-skill workers that follows from the increase in $s_{2}$ is greater on high-skill jobs. The reason is that on high-skill jobs there is both a direct effect $\left(s_{2}\right.$ increases; i.e., high-skill workers produce more on high-skill jobs) and an indirect effect $\left(r U\left(s_{2}\right)\right.$ increases, so the bargaining position of the high-skilled improves), whereas on low-skill jobs, only the indirect effect operates. We also find that the increased productivity of high-skill jobs leads to an increase in aggregate output (from .929 to .932).

Row 3 of the first panel of Table 1 shows the effects of increasing $s_{2}$ to 1.3. Setting $s_{2}=1.3$ leads to the existence of both types of equilibria. Comparing the ex post segmentation equilibrium at $s_{2}=1.3$ (row 1, panel 2) with the corresponding cross-skill matching equilibrium (row 3, panel 1), we see a dramatic fall in $\phi$ (from .779 in the cross-skill matching case to .545 in the $e x$ post segmentation case). The reason is that if high-skill workers only accept 
high-skill jobs, then employers find it worthwhile to close down low-skill vacancies and open up high-skill vacancies. Unemployment increases among both types of workers leading to a large increase in overall unemployment (from .084 to .130). The increase in unemployment among the high-skill workers, who now find it worthwhile to wait for the better jobs, dominates so that $\gamma$ falls. Note that $w_{22}-w_{11}$ rises, i.e., there is an increase in wage dispersion, and output also rises.

Both types of equilibria also coexist at $s_{2}=1.35$, but at $s_{2}=1.40$, there is only an ex post segmentation equilibrium. The second panel of Table 1 illustrates the effect of increasing $s_{2}$ across ex post segmentation equilibria. Once the market is segmented, skill-biased technical change has only a minor effect on the low-skill sector. This is evident in the small effect on $\gamma$ and on $w_{11}$. There is an increase in vacancies in the high-skill market leading to a decrease in $\phi$ and $u$ and to increases in $w_{22}$ and $Y$.

In sum, our model suggests that skill-biased technical change leads both to increased wage inequality and to increased unemployment in cross-skill matching equilibria. In such equilibria, when high-skill workers take lowskill jobs, the increased wage inequality operates both within and between skill groups. The increase in unemployment is particularly strong when the increase in $s_{2}$ is large enough to trigger a switch to an equilibrium with ex post segmentation. The effect of increasing $s_{2}$ is unambiguously one of making the high-skill workers better off and the low-skill workers worse off. The deleterious effects of skill-biased technical change on the welfare of low-skill workers comes about even though these workers are no less productive in an absolute sense than they were before the change. Once the labor market is completely segmented, the effect on unemployment is reversed, but there is still increasing wage inequality.

In order to separate the effect of increasing $s_{2}$, i.e., making the high-skill jobs more productive, from the change in the relative productivity of the two types of jobs, we also examine the effects of changing relative productivity via changes in $s_{1}$. A reduction in $s_{1}$ could be caused by the introduction of cheap imports, reducing the value of the output on low-skill jobs. The effects of changing $s_{1}$ are shown in Table 2 , where we assume that $s_{2}=1.2{ }^{13}$ As noted in discussing equation (19), $\frac{\partial \theta}{\partial s_{1}}>0$ so that a decrease in $s_{1}$ leads to a fall in $\theta$. As one would expect with a lower $s_{1}, u$ increases and the fraction

\footnotetext{
${ }^{13}$ We continue to assume that $s_{2}=1.2$ in the rest of this section.
} 
of unemployed who are low skill, $\gamma$, rises, while the fraction of vacancies that are low skill falls. When $s_{1}$ falls, the wages of both low-skill and high-skill workers decrease as does aggregate output. It is interesting to note that when we increase $s_{1}$, we reach a corner solution in which all the vacancies are low skill.

Table 2: Comparative Statics for $s_{1}$

Solution with $m(\theta)=2 \theta^{\frac{1}{2}}$

\begin{tabular}{rcccccccccc} 
Assumptions: & \multicolumn{4}{c}{$s_{2}=1.2, p=\frac{2}{3}, b=.1, \beta=.5, \delta=.2, c=.3, r=.05$} \\
$s_{1}$ & $\theta$ & $m$ & $u$ & $\gamma$ & $\phi$ & $w_{11}$ & $w_{21}$ & $w_{22}$ & $Y$ \\
.975 & 1.60 & 2.53 & .078 & .686 & .907 & .624 & .636 & .749 & .906 \\
1 & 1.68 & 2.59 & .072 & .670 & .983 & .651 & .653 & .753 & .929 \\
1.025 & 1.75 & 2.65 & .070 & $\frac{2}{3}$ & 1.000 & .675 & .675 & -- & .953
\end{tabular}

It is interesting to compare these results with those in Table 1. If the relative productivity of high-skill jobs increases via an increase in $s_{2}, \theta$ is unaffected, $u$ and $\gamma$ rise, while $\phi$ falls. Wages of low-skill workers fall, while those of high-skill workers on both low-skill and high-skill jobs rise, but rise relatively more on high-skill jobs, i.e., the wage distribution becomes less equal both between and within skill groups. When the relative productivity of high-skill jobs increases via a decrease in $s_{1}, \theta$ falls, but the direction of the effects on $u, \gamma$, and $\phi$ are the same as for an increase in $s_{2}$. The wages for all workers, however, fall. The wages of high-skill workers fall by much more in low-skill jobs than in high-skill jobs. Thus, when $s_{1}$ falls, there is also a spreading of the wage distribution among high-skill workers, but they all suffer a wage loss in contrast to the wage gain when $s_{2}$ rises. If the productivity of the low-skill jobs falls further, the model yields multiple equilibria and eventually only an ex post segmentation equilibrium.

Another skill-related comparative static effect is investigated in Table 3, which reports results showing the effects of changing the fraction of the workforce that is low-skill, $p$. The third row of Table 3 repeats row 1 of the first panel of Table 1. Increasing the fraction of low-skill workers makes creating low-skill vacancies more attractive. The fraction of vacancies that are lowskill rises from .657 when $p=.5$ to .834 when $p=.6$. When $p$ rises to .7, there is a collapse of the high-skill market; i.e., $\phi=1$. In this corner solution, only low-skill vacancies are created, unemployment rates are the same for low-skill and high-skill workers (so $\gamma=p$ ), and low-skill and high-skill workers are paid the same wage on the only type of job that exists in the economy. 
Note that so long as there is a cross-skill matching equilibrium, $\theta$ is independent of $p$ (cf., equation (19)). The unemployment rate, however, declines as $p$ rises. The reason is that the proportion of vacancies that are low-skill rises, reducing the unemployment duration of low-skill workers. Another point to note is that the low-skill wage is higher and both high-skill wages are lower as a result of the increase in $p$. As $p$ increases, the corresponding adjustment in $\phi$ increases the value of unemployment for the low-skill but decreases the high-skill workers' unemployment value so wage inequality decreases. Finally, as $p$ rises, aggregate output falls reflecting the reduced potential for high-skill production.

Table 3: Comparative Statics for $p$ Solution with $m(\theta)=2 \theta^{\frac{1}{2}}$

\begin{tabular}{cccccccccc} 
Assumptions: & \multicolumn{4}{c}{$s_{1}=1, s_{2}=1.2, b=.1, \beta=.5, \delta=.2, c=.3, r=.05$} \\
$p$ & $\theta$ & $m$ & $u$ & $\gamma$ & $\phi$ & $w_{11}$ & $w_{21}$ & $w_{22}$ & $Y$ \\
.5 & 1.68 & 2.59 & .088 & .595 & .657 & .632 & .680 & .780 & .943 \\
.6 & 1.68 & 2.59 & .080 & .639 & .834 & .644 & .665 & .765 & .933 \\
$\frac{2}{3}$ & 1.68 & 2.59 & .072 & .670 & .983 & .651 & .653 & .753 & .929 \\
.7 & 1.68 & 2.59 & .072 & .700 & 1.000 & .651 & .651 & --- & .928
\end{tabular}

In Table 4, we look at the effects of varying $b$. We have interpreted $b$ as the value of leisure, but this parameter could alternatively be interpreted as unemployment compensation, if it were financed by a nondistorting tax. As shown above, in cross-skill matching equilibria, when $b$ increases, $\theta$ falls. The expected duration of unemployment increases, and the expected duration of a vacancy falls. As a result, it becomes relatively more attractive to open high-skill vacancies; i.e., $\phi$ falls as $b$ increases. As $\phi$ declines, there is a corresponding increase in $\gamma$; i.e., the average duration of unemployment among low-skill workers rises relative to that among high-skill workers. As a consequence, the value of unemployment for high-skill workers begins to increase relative to the corresponding value for the low-skill unemployed, and this generates more wage dispersion within low-skill jobs. That is, $w_{21}-w_{11}$ increases. In addition, output declines as $b$ increases. Note, however, that the dominant features of the baseline equilibrium continue to prevail; namely, the majority of vacancies are low-skill, and most wage dispersion is between rather than within job types. 
Table 4: Comparative Statics for $b$

Solution with $m(\theta)=2 \theta^{\frac{1}{2}}$

Assumptions: $s_{2}=1.2, s_{1}=1, p=\frac{2}{3}, \beta=.5, \delta=.2, c=.3, r=.05$

$\begin{array}{cccccccccc}b & \theta & m & u & \gamma & \phi & w_{11} & w_{21} & w_{22} & Y \\ .1 & 1.68 & 2.59 & .072 & .670 & .983 & .651 & .653 & .753 & .929 \\ .2 & 1.37 & 2.34 & .082 & .682 & .928 & .653 & .662 & .762 & .922 \\ .3 & 1.07 & 2.07 & .096 & .696 & .862 & .656 & .672 & .772 & .912\end{array}$

Our final comparative statics exercise examines the effect of increasing $\beta$, the workers' share of the net surplus. Table 5 shows the effects of increasing $\beta$ from 0.4 to 0.6 . An increase in $\beta$ causes wages to rise but also causes unemployment to increase. The wage effect indicates that the increased share of the net surplus that workers receive when employed more than offsets any weakening in the workers' bargaining position that could result from the increase in unemployment.

Table 5: Comparative Statics for $\beta$

Solution with $m(\theta)=2 \theta^{\frac{1}{2}}$

Assumptions: $s_{1}=1, s_{2}=1.2, b=.1, p=\frac{2}{3}, \delta=.2, c=.3, r=.05$

$\begin{array}{cccccccccc}\beta & \theta & m & u & \gamma & \phi & w_{11} & w_{21} & w_{22} & Y \\ .4 & 2.51 & 3.17 & .060 & .668 & .994 & .640 & .641 & .721 & .941 \\ .5 & 1.68 & 2.59 & .072 & .670 & .983 & .651 & .653 & .753 & .929 \\ .6 & 1.11 & 2.11 & .087 & .668 & .994 & .660 & .661 & .781 & .913\end{array}$

\section{Conclusions}

We have built a model that highlights the role of skill in the labor market. By our definition of skill, low-skill workers can only do low-skill jobs, while high-skill workers can do both low- and high-skill jobs. High-skill workers are, however, no more productive on low-skill jobs than low-skill workers are. This definition makes it possible to examine how low-skill and high-skill jobs interact, in addition to the usual interaction between low-skill and high-skill workers.

Depending on the underlying parameter configuration, our model has two types of equilibria. In the first type of equilibrium, it is worthwhile for high-skill workers to match with low-skill vacancies, i.e., there is cross-skill 
matching. The second type of equilibrium is one in which it is not worthwhile for high-skill workers to take low-skill jobs. The low- and high-skill markets separate endogenously in this case; that is, there is ex post segmentation.

Our model has some striking comparative statics properties. A parameter shift that we interpret as skill-biased technical change increases wage dispersion both within (in equilibria with cross-skill matching) and between skill groups and increases unemployment, especially among low-skill workers. We also examined the effects of reducing the value of low-skill production (interpreted as cheap import competition), of changing the underlying skill mix in the worker population and of changing workers' leisure values and bargaining strength.

The model could be extended in a number of ways. It would give a richer description of reality if there were more than two skill levels or onthe-job search. These and other possible extensions, however, would take us well beyond the objectives of the current paper, namely, to demonstrate the usefulness of a relatively simple model of this type for understanding the role of skill in the labor market and specifically the role of skill-biased technical change.

\section{References}

[1] Acemoglu, Daron (1998) "Changes in Unemployment and Wage Inequallity: An Alternative Theory and Some Evidence," NBER Working Paper 6658 .

[2] Acemoglu, Daron (1999) "Patterns of Skill Premia," NBER Working Paper 7018.

[3] Beaudry, Paul and David Green (1999), "What is Driving US and Canadian Wages: Exogenous Technical Change or Exogenous Choice of Technique?," mimeo.

[4] Berman, Eli, John Bound, and Stephen Machin (1998), "Implications of Skill-Biased Technological Change: International Evidence," Quarterly Journal of Economics, vol 113, pp 1245-80.

[5] Bound, John and George Johnson (1992), "Changes in the Structure of Wages in the 1980's: An Evaluation of Alternative Explanations," American Economic Review, vol 77, pp 371-92. 
[6] Burdett, Kenneth and Dale Mortensen (1998) "Wage Differentials, Unemployment, and Employer Size," International Economic Review, vol 39 , pp 257-273.

[7] Diamond, Peter (1982) "Aggregate Demand Management in Search Equilibrium," Journal of Political Economy, vol 90, pp 881-94.

[8] Gautier, Pieter A. (1999) "Unemployment and Search Externalities in a model with Heterogeneous Jobs and Heterogeneous Workers," mimeo.

[9] Heckman, James, Lance Lochner, and Christopher Taber (1998), "Explaining Rising Wage Inequality: Explorations with a Dynamic General Equilibrium Model of Labor Earnings with Heterogeneous Agents," Review of Economic Dynamics, vol 1, pp 1-58.

[10] Katz, Lawrence and Kevin Murphy (1992) "Changes in Relative Wages, 1963-1987: Supply and Demand Factors," Quarterly Journal of Economics, vol 107, pp 35-78.

[11] Krugman, Paul (1994) "Past and Prospective Causes of High Unemployment," in Reducing Unemployment: Current Issues and Policy Options, A Symposium Sponsored by the Federal Reserve Bank of Kansas City, Jackson Hole, Wyoming, August 1994.

[12] Machin, Stephen (1996), "Wage Inequality in the U.K.," Oxford Review of Economic Policy, vol 12, pp 47-64.

[13] Machin, Stephen and Alan Manning (1997), "Can Supply Create its Own Demand? Implications for Rising Skill Differentials," European Economic Review, Papers and Proceedings, vol 41, pp 507-16.

[14] McKenna, C.J. (1996), "Education and the Distribution of Unemployment," European Journal of Political Economy, vol 12, pp 113-32.

[15] Mortensen, Dale (1982) "Property Rights in Mating, Racing, and Related Games," American Economic Review, vol 72, pp 968-79.

[16] Mortensen, Dale and Christopher Pissarides (1994), "Job Creation and Job Destruction in the Theory of Unemployment," Review of Economic Studies, vol 61, pp 397-415. 
[17] Mortensen, Dale and Christopher Pissarides (1999) "Unemployment Responses to 'Skill-Biased' Technology Shocks: The Role of Labour Market Policy," Economic Journal, vol 109, pp 242-65.

[18] Organization for Economic Cooperation and Development (1994), Jobs Study, Paris: OECD.

[19] Pissarides, Christopher (1990) Equilibrium Unemployment Theory, (Basil Blackwell, Oxford)

[20] Saint-Paul, Gilles (1996) "Are the Unemployed Unemployable?" European Economic Review, vol 40, pp 1501-19.

[21] Sicherman, Nachum (1991), "Overeducation in the Labor Market," Journal of Labor Economics, vol 9, pp 101-12.

[22] van den Berg, Gerard, Pieter Gautier, Jan van Ours, and Geert Ridder (1998) "Worker Turnover at the Firm Level and Crowding Out of Lower Educated Workers," mimeo, July 1998.

[23] Vroman, Susan (1987) "Behavior of the Firm in a Market for Heterogeneous Labor," Journal of Economic Dynamics and Control, vol 11, pp 313-29.

[24] Wood, Adrian (1994) North-South Trade, Employment and Inequality: Changing Fortunes in a Skill-Driven World, (Clarendon, Oxford). 
Figure 1: 